\title{
Pemodelan Jumlah Kematian Ibu di Provinsi Sulawesi Selatan Menggunakan Regresi Binomial Negatif
}

\author{
Adnan Sauddin \\ Universitas Islam Negeri Alauddin Makassar,adnan.sauddin@uin-alauddin.ac.id \\ Nur Indah Auliah, \\ Universitas Islam Negeri Alauddin Makassar \\ Wahidah Alwi \\ Universitas Islam Negeri Alauddin Makassar,Wahidah.alwi@uin-alauddin.ac.id
}

\begin{abstract}
ABSTRAK, Kematian ibu merupakan indikator penting untuk mengukur derajat kesehatan masyarakat suatu daerah. Jumlah kematian ibu di Provinsi Sulawesi Selatan tahun 2017 terbilang masih cukup tinggi sebanyak 115 kasus. Oleh karena itu, diperlukan suatu analisis untuk mengetahui faktor apa yang signifikan berpengaruh terhadap jumlah kematian ibu. Dalam penelitian ini, jumlah kematian ibu dapat dimodelkan menggunakan analisis regresi poisson. Akan tetapi, pada model tersebut terjadi masalah overdispersi sehingga analisis dilanjutkan menggunakan analisis regresi binomial negatif sehingga diperoleh hasil dengan dua variabel yang signifikan berpengaruh terhadap jumlah kematian ibu yaitu variabel persalinan ditolong tenaga kesehatan $\left(X_{3}\right)$ dan variabel ibu nifas mendapat vitamin A $\left(X_{9}\right)$ dengan model regresi binomial negatif $\left(\mu_{i}\right)=\exp \left(10,374-0,301 X_{3}+0,208 X_{9}\right)$.
\end{abstract}

Kata Kunci: Kematian ibu,overdispersi, regresi binomial negatif

\section{PENDAHULUAN}

Kematian ibu merupakan salah satu faktor pendukung dalam menilai sejauh mana tingkat kesejahteraan masyarakat suatu wilayah salah satunya di bidang kesehatan. Salah satu provinsi dengan jumlah kematian ibu yang masih cukup tinggi yaitu Provinsi Sulawesi Selatan. Berdasarkan data Dinas Kesehatan Provinsi Sulawesi Selatan, jumlah kematian ibu di Provinsi Sulawesi Selatan pada tahun 2016 sebesar 153 orang per 100.000 kelahiran hidup dan pada tahun 2017 jumlahnya sebesar 115 orang per 100.000 kelahiran hidup[1].

Kasus kematian ibu yang masih cukup tinggi di Provinsi Sulawesi Selatan menunjukkan bahwa kualitas kesehatannya masih cukup rendah. Tingginya jumlah kematian ibu dapat dipengaruhi oleh berbagai faktor di antaranya komplikasi kebidanan, proses persalinan tidak dilakukan oleh tenaga kesehatan, kurang memadainya pelayanan kesehatan ibu hamil maupun nifas.

Menurunkan jumlah kasus kematian ibu dapat dilakukan dengan memahami dan mempelajari faktor-faktor apa saja yang dapat menyebabkan kematian pada ibu baik pada saat masa kehamilan, persalinan dan pasca persalinan.

Penelitian terkait bidang kesehatan salah satunya kasus kematian dan faktor penyebabnya telah banyak dilakukan dengan menggunakan berbagai metode salah satunya yaitu analisis regresi poisson. Analisis regresi poisson merupakan salah satu metode yang paling sering digunakan untuk menganalisis hubungan antara variabel respon dan variabel penjelas terkait dengan bidang kesehatan.

Analisis regresi poisson memiliki asumsi variansi dan mean dari variabel respon harus sama. Akan tetapi, pada data count sering dijumpai kondisi dimana nilai variansi lebih besar dari nilai mean atau yang sering disebut dengan overdispersi. Oleh karena itu, analisis harus dilanjutkan salah satunya dengan menggunakan analisis regresi binomial negatif.

Salah satu penelitian yang menggunakan analisis regresi binomial untuk mengatasi masalah overdispersi yaitu penelitian yang dilakukan oleh M. Ali Ma'sum (2013) dengan studi kasus angka kematian ibu di Provinsi Jawa Timur tahun 2011. Dari hasil analisis, dari sembilan variabel yang digunakan terdapat satu variabel yang berpengaruh secara signifikan terhadap jumlah kematian ibu yaitu jumlah ibu nifas mendapat vitamin $\mathrm{A}[2]$.

Oleh karena itu, untuk memodelkan jumlah kematian ibu beserta faktor-faktor yang mempengaruhinya pada penelitian ini akan menggunakan analisis regresi binomial negatif. Penggunaan analisis regresi binomial negatif karena pada metode ini tidak mengasumsikan 
bahwa nilai variansi harus sama dengan nilai mean.

\section{TINJAUAN PUSTAKA}

\section{DISTRIBUSI BINOMIAL NEGATIF}

Suatu percobaan bernoulli bebas yang terdiri dari $n$ usaha berulang akan menghasilkan dua kemungkinan yaitu sukses dengan peluang $p$ dan gagal dengan peluang $q=1-p$, di mana $x$ dinyatakan sebagai banyaknya percobaan yang diperlukan untuk memperoleh $k$ sukses dalam $n$ usaha bebas[3]. Maka distribusi peluang peubah acak $x$ disebut sebagai distribusi binomial negatif yang diberikan sebagai berikut:

$$
f(x)=\left(\frac{x-1}{k-1}\right) p^{k}(1-p)^{x-k}, \mathrm{x}=\mathrm{k}, \mathrm{k}+1, \mathrm{k}+2, \ldots
$$

\section{UJI OVERDISPERSI}

Overdispersi adalah pelanggaran asumsi yang terjadi apabila nilai variansi variabel respon lebih besar dari nilai mean nya atau $V(Y)>E(Y)$. Kasus overdispersi dapat terjadi karena adanya pencilan pada data, pengamatan yang hilang pada peubah penjelas, terjadinya korelasi antar pengamatan dan perlunya transformasi pada peubah penjelas[4]. Kondisi overdispersi dapat diketahui dengan melihat nilai deviansi/derajat bebas dan Pearson Chi-Square/bebas keduanya menghasilkan nilai yang lebih besar dari 1 . Statistik uji nilai deviansnya sebagai berikut[5]:

$$
\begin{aligned}
D=2 & \sum_{i=1}^{n}\left[y_{i} \ln \left(\frac{y_{i}}{y_{i}}\right)-\left(y_{i}-y_{i}\right)\right] \\
D & =\text { Nilai deviansi } \\
y_{i} & =\text { Nilai sebenarnya respon amatan ke- } i \\
y_{i} & =\text { Nilai dugaan respon amatan ke- } i
\end{aligned}
$$

Untuk nilai Pearson Chi-Square diperoleh dari persamaan sebagai berikut:

$$
x^{2}=\sum_{i=1}^{n} \frac{\left(y_{i}-\frac{y_{i}}{2}\right)^{2}}{y_{i}}
$$

$X^{2}=$ Nilai pearson chi-square

$y_{i}=$ Nilai sebenarnya respon amatan ke- $i$

$\hat{y}_{i}=$ Nilai dugaan respon amatan ke- $i$

\section{MODEL REGRESI BINOMIAL NEGATIF}

Model regresi binomial negatif merupakan model yang berasal dari distribusi poisson- gamma mixture yang merupakan penerapan dari General Linear Model yang menggambarkan hubungan antara variabel dependen dengan variabel independen. Regresi binomial negatif biasanya digunakan untuk memodelkan data dengan variabel respon berupa data count. Regresi binomial negatif digunakan sebagai alternatif dari model regresi poisson yang mengalami overdispersi (var>mean). Model regresi binomial negatif mengasumsikan bahwa peubah respon berganda dapat dituliskan sebagai berikut[6]:

$$
\begin{gathered}
\ln \left(\mu_{i}\right)=\beta_{0}+\beta_{1} X_{i 1}+\ldots+\beta_{k} X_{i k}+\varepsilon_{i} \\
\mu_{i}=e^{\beta_{0}+\beta_{1} X_{i 1}+\ldots+\beta_{k} X_{i k}+\varepsilon_{i}}
\end{gathered}
$$

$\mu_{i} \quad=$ Nilai ekspektasi dari $y_{i}$ yang berdistribusi binomial negatif

$\beta_{0} \quad=$ Nilai Konstanta

$X_{i 1} \quad=$ Nilai variabel independen ke- $i$

$\beta_{k}=$ Nilai koefisien variabel independen ke$k$

\section{PENAKSIRAN PARAMETER DENGAN METODE MAXIMUM LIKELIHOOD}

Parameter dalam model regresi binomial negatif yang tidak diketahui nilainya, yaitu $\beta_{0}, \beta_{1}, \ldots$, $\beta_{p}$ perlu ditaksir. Penaksiran parameter dapat dilakukan menggunakan metode maximum likelihood. Langkah-langkah penafsiran parameter sebagai berikut:

1. Membentuk fungsi likelihood

$$
\begin{aligned}
& L(\beta, k)=\prod_{i=1}^{n} f\left(y_{i} ; \beta ; \alpha\right) \\
& =\prod_{i=1}^{n} \frac{\Gamma\left(y_{i}+\frac{1}{\alpha}\right)}{y_{i} ! \Gamma\left(\frac{1}{\alpha}\right)}\left(\frac{\alpha \exp \left(x_{i}^{\prime} \beta\right)}{1+\alpha \exp \left(x_{i}^{\prime} \beta\right)}\right)^{y_{i}}\left(\frac{1}{1+\alpha \exp \left(x_{i}^{\prime} \beta\right)}\right)^{\frac{1}{\alpha}}
\end{aligned}
$$

2. Membentuk fungsi log dari fungsi likelihood yang telah diperoleh

$$
\begin{aligned}
& L(\beta, \alpha)=\ln L(\beta, \alpha) \\
= & \ln \prod_{i=1}^{n}\left\{\prod_{r=0}^{y_{i}-1}(1+\alpha r)\left(\frac{1}{y_{i} !}\right)\left(\frac{\exp \left(x_{i}^{\prime} \beta\right)}{1+\alpha \exp \left(x_{i}^{\prime} \beta\right)}\right)^{y_{i}}\left(\frac{1}{1+\alpha \exp \left(x_{i}^{\prime} \beta\right)}\right)^{\frac{1}{\alpha}}\right\}
\end{aligned}
$$

3. Memaksimumkan fungsi $\ln L(\beta, \alpha)$ dapat dilakukan dengan mencari turunan masingmasing parameter $\beta$ dan $\alpha$ kemudian disamakan nol. Untuk menentukan penaksir 
kemungkinan maksimumnya, digunakan metode iteratif yang cukup rumit. Metode iteratif atau numerik yang digunakan untuk memperoleh penaksir parameter dalam model regresi binomial negatif adalah dengan menggunakan metode Newton Rhapson[7].

\section{PENGUJIAN PARAMETER MODEL REGRESI BINOMIAL NEGATIF}

Pengujian parameter dilakukan untuk melihat pengaruh variabel independen terhadap variabel dependen. Pengujian parameter dilakukan menggunakan dua uji yaitu uji serentak (overall) dan uji parsial.

\section{Uji Overall}

Uji overall dilakukan untuk melihat pengaruh secara serentak variabel independen terhadap variabel dependen pada model. Adapun rumusan hipotesis pada uji overall:

$$
\begin{aligned}
& H_{0}: \beta_{1}=\ldots=\beta_{j}=0 \\
& H_{1}: \beta_{j} \neq 0
\end{aligned}
$$

Statistik uji yang digunakan adalah sebagai berikut:

$$
\begin{aligned}
G & =-2 \log \frac{L_{0}}{L_{1}} \\
& =-2\left(\log L_{0}-\log L_{1}\right)
\end{aligned}
$$

Statistik Uji G mengikuti distribusi chi-square sehingga dibandingkan dengan tabel chisquare dengan derajat bebas db (banyaknya variabel), dengan daerah penolakan $H_{0}$ jika $G>X_{(\alpha, d b)}^{2}$ atau berdasarkan $p$-value yang dibandingkan dengan nilai $\alpha$, dengan daerah penolakan $p$-value $<\alpha=0,05$.

\section{Uji Parsial}

Uji Parsial digunakan untuk melihat pengaruh variabel independen terhadap variabel dependen secara individu. Adapun rumusan hipotesis pada uji parsial:

$$
\begin{aligned}
& H_{0}: \beta_{j}=0 \\
& H_{1}: \beta_{j} \neq 0
\end{aligned}
$$

Statistik uji yang digunakan adalah uji Wald dengan rumus sebagai berikut:

$$
W=\left(\frac{\beta_{j}}{S E\left(\beta_{j}\right)}\right)^{2}
$$

Dimana nilai Uji W mengikuti distribusi chisquare sehingga dibandingkan dengan chisquare tabel $X_{(a, d b=1)}^{2}$. Maka kriteria uji untuk pengambilan keputusan dengan taraf nyata $(\alpha)$ adalah tolak $H_{0}$ jika nilai $W>X_{(a, d b=1)}^{2}$ dan dapat dilihat berdasarkan $p-$ value $<\alpha$, di mana nilai $\alpha=0,05[8]$.

\section{ANGKA KEMATIAN IBU}

Kematian ibu merupakan kematian perempuan pada saat hamil atau kematian dalam kurun waktu 42 hari sejak terminasi atau akhir kehamilan yang disebabkan karena kehamilannya atau pengelolaannya, akan tetapi bukan karena sebab lain seperti kecelakaan, terjatuh dan lain-lain, atau dengan kata lain kematian merupakan banyaknya wanita yang meninggal dari suatu penyebab kematian terkait dengan gangguan kehamilan[9].

\section{METODOLOGI}

\section{Sumber Data}

Data yang digunakan merupakan data sekunder yang diperoleh dari Dinas Kesehatan Provinsi Sulawesi Selatan tahun 2017 terkait dengan kematian ibu.

\section{Variabel Penelitian}

Variabel yang digunakan pada penelitian ini terdiri dari sembilan variabel independen dan satu variabel dependen yang dapat dilihat pada tabel di bawah ini:

Tabel 3.1 Variabel Penelitian

\begin{tabular}{|l|c|l|}
\hline $\begin{array}{l}\text { Variabel } \\
\text { dependen }\end{array}$ & $Y$ & Jumlah kematian ibu \\
\hline \multirow{5}{*}{$\begin{array}{l}\text { Variabel } \\
\text { Independen }\end{array}$} & $X_{1}$ & $\begin{array}{l}\text { Perilaku hidup bersih } \\
\text { dan sehat }\end{array}$ \\
\cline { 2 - 3 } & $X_{2}$ & $\begin{array}{l}\text { Penanganan komplikasi } \\
\text { kebidanan }\end{array}$ \\
\cline { 2 - 3 } & $X_{3}$ & $\begin{array}{l}\text { Persalinan ditolong } \\
\text { tenaga kesehatan }\end{array}$ \\
\cline { 2 - 3 } & $X_{4}$ & $\begin{array}{l}\text { Pelayanan kesehatan ibu } \\
\text { hamil (K1) }\end{array}$ \\
\cline { 2 - 3 } & $X_{5}$ & $\begin{array}{l}\text { Pelayanan kesehatan ibu } \\
\text { hamil (K4) }\end{array}$ \\
\hline
\end{tabular}




\begin{tabular}{|l|l|l|}
\hline & $X_{6}$ & $\begin{array}{l}\text { Ibu hamil memperoleh } \\
\text { tablet Fe1 30 tablet }\end{array}$ \\
\cline { 1 - 3 } & $X_{7}$ & $\begin{array}{l}\text { Ibu hamil memperoleh } \\
\text { tablet Fe3 90 tablet }\end{array}$ \\
\cline { 2 - 3 } & $X_{8}$ & $\begin{array}{l}\text { Pelayanan kesehatan } \\
\text { nifas }\end{array}$ \\
\cline { 2 - 3 } & $X_{9}$ & $\begin{array}{l}\text { Ibu nifas mendapat } \\
\text { vitamin A }\end{array}$ \\
\hline
\end{tabular}

\section{Prosedur Penelitian}

Adapun langkah-langkah analisis pada penelitian ini adalah sebagai berikut:
a. Mendeskripsikan data
b. Melakukan uji overdispersi
c. Membentuk model regresi binomial negatif
d. Uji signifikansi parameter model regresi binomial negatif

1. Uji overall

2. Uji parsial

e. Interpretasi hasil analisis

\section{PEMBAHASAN}

\section{Deskripsi Data}

Nilai statistik untuk setiap variabel yang digunakan pada penelitian ini disajikan pada tabel berikut:

Tabel 4.1 Statistika Deskriptif

\begin{tabular}{|l|r|r|r|r|}
\hline Variabel & Mean & \multicolumn{1}{l|}{ Variansi } & Min & \multicolumn{1}{l|}{ Maks } \\
\hline Y & 4,791 & 7,911 & 1 & 13 \\
\hline X1 & 55,949 & 205,660 & 36,300 & 80,950 \\
\hline X2 & 82,933 & 293,736 & 54,150 & 118,030 \\
\hline X3 & 94,407 & 11,429 & 85,150 & 100,410 \\
\hline X4 & 99,351 & 10,108 & 93,760 & 105,300 \\
\hline X5 & 90,015 & 32,754 & 78,010 & 98,490 \\
\hline X6 & 97,350 & 50,474 & 72,490 & 110,300 \\
\hline X7 & 87,325 & 53,996 & 69,300 & 97,310 \\
\hline X8 & 91,922 & 21,649 & 79,470 & 98,910 \\
\hline X9 & 94,166 & 16,511 & 80,700 & 100,410 \\
\hline
\end{tabular}

Dari nilai statistik yang disajikan pada tabel 4.1, diketahui bahwa nilai variansi lebih besar dari nilai mean (var $>$ mean $=7,911>4,791$ ) untuk variabel dependen $\mathrm{Y}$. Hal tersebut menunjukkan bahwa terjadi kasus overdispersi pada data tersebut. Oleh karena itu, data tersebut memenuhi asumsi regresi binomial negatif.

\section{Uji Overdispersi}

Overdispersi merupakan asumsi yang harus dipenuhi untuk menggunakan regresi binomial negatif. Oleh karena itu, dilakukan uji dispersi untuk membuktikan bahwa data tersebut memenuhi asumsi regresi binomial negatif. Dari hasil analisis membuktikan bahwa data tersebut memenuhi asumsi. Nilai overdispersi dapat dilihat pada tabel di bawah ini:

Tabel 4.2 Uji Dispersi

\begin{tabular}{lll}
\hline Deviansi & $d f$ & Dispersi \\
\hline 14,775 & 14 & 1,055 \\
\hline
\end{tabular}

Berdasarkan tabel 4.2, diperoleh nilai dispersi $>$ 1, sehingga disimpulkan bahwa data tersebut mengalami overdispersi. Hal ini menunjukkan bahwa regresi binomial negatif tepat digunakan untuk memodelkan jumlah kematian ibu.

\section{Model Regresi Binomial Negatif}

Setelah uji overdispersi terpenuhi, langkah selanjutnya adalah membentuk model regresi binomial negatif terkait jumlah kematian ibu dengan nilai estimasi parameter yang disajikan pada tabel berikut:

Tabel 4.3 Nilai Estimasi Parameter

\begin{tabular}{ccl}
\hline Parameter & Nilai Dugaan & $\operatorname{Pr}(>|\mathrm{z}|)$ \\
\hline$\beta_{0}$ & 13,267288 & 0,004518 \\
$\beta_{1}$ & $-0,016614$ & 0,068684 \\
$\beta_{2}$ & $-0,006993$ & 0,433300 \\
$\beta_{3}$ & $-0,583428$ & 0,0000858 \\
$\beta_{4}$ & 0,101846 & 0,246425 \\
$\beta_{5}$ & 0,041228 & 0,231113 \\
$\beta_{6}$ & $-0,015346$ & 0,625931 \\
$\beta_{7}$ & $-0,021548$ & 0,505117 \\
$\beta_{8}$ & $-0,059660$ & 0,051396 \\
$\beta_{9}$ & $-0,422888$ & 0,000437 \\
\hline
\end{tabular}

Berdasarkan tabel 4.3 diperoleh model regresi binomial negatif yaitu:

$$
\begin{aligned}
\left(\mu_{i}\right) & =\exp \left(13,267288-0,016614 X_{1}-0,006993 X_{2}-\right. \\
& 0,583428 X_{3}+0,101846 X_{4}+0,041228 X_{5}- \\
& 0,015346 X_{6}-0,021548 X_{7}-0,059660 X_{8}- \\
& 0,422888 X_{9}
\end{aligned}
$$

\section{Uji Overall Parameter Model Regresi Binomial Negatif}

Pengujian parameter secara serentak dilakukan dengan membandingkan nilai Likelihood Ratio 
(G) dengan nilai Chi-Square atau membandingkan nilai $p$-value dengan $\alpha$ yang disajikan pada tabel di bawah ini:

Tabel 4.4 Uji Overall

\begin{tabular}{lccc}
\hline $\mathrm{G}$ & $\chi_{0.05,9}^{2}$ & $p$-value & $\alpha$ \\
\hline 19,153 & 16,919 & 0,023 & 0,05 \\
\hline
\end{tabular}

Berdasarkan tabel 4.4, diperoleh nilai $G=$ $19,153>$ nilai $\chi_{0.05,9}^{2}=16,919$ dan nilai Nilai $p$-value $=0,023<\alpha=0,05$ yang berarti tolak $H_{0}$. Hal tersebut menunjukkan bahwa variabel independen mempengaruhi variabel dependen secara serentak.

\section{Uji Parsial Parameter Model Regresi Binomial Negatif}

Pengujian parameter secara parsial dilakukan dengan memperhatikan nilai wald yang disajikan pada tabel di bawah ini:

Tabel 4.5 Uji Parsial

\begin{tabular}{|c|c|c:c|c|}
\hline Variabel & $\beta$ & Nilai W & $\chi_{0.05,1}^{2}$ & Keputusan \\
\hline$X_{1}$ & $-0,016614$ & 3,314267 & 3,841 & Terima $H_{0}$ \\
\hdashline$X_{2}$ & $-0,006993$ & 0,6139188 & 3,841 & Terma $H_{0}$ \\
\hline$X_{3}$ & $-0,583428$ & 15,42639 & 3,841 & Tolak $H_{0}$ \\
\hline$X_{4}$ & 0,101846 & 1,343465 & 3,841 & Terima $H_{0}$ \\
\hline$X_{5}$ & 0,041228 & 0,01434 & 3,841 & Terima $H_{0}$ \\
\hline$X_{6}$ & $-0,015346$ & 0,237611 & 3,841 & Terima $H_{0}$ \\
\hline$X_{7}$ & $-0,021548$ & 0,44417 & 3,841 & Terma $H_{0}$ \\
\hline$X_{8}$ & $-0,059660$ & 3,79527 & 3,841 & Terma $H_{0}$ \\
\hline$X_{9}$ & 0,422888 & 12,36828 & 3,841 & Tolak $H_{0}$ \\
\hline
\end{tabular}

Berdasarkan tabel 4.5, diperoleh hasil bahwa variabel yang signifikan berpengaruh terhadap jumlah kematian ibu di Provinsi Sulawesi Selatan yaitu variabel $X_{3}$ dan $X_{9}$. Di mana $X_{3}$ merupakan persalinan ditolong tenaga kesehatan dan variabel $X_{9}$ merupakan ibu nifas mendapat vitamin A. Dengan menggunakan persamaan (0.4), diperoleh model regresi binomial negatif berdasarkan tabel 4.5, yaitu:

$$
\left(\mu_{i}\right)=\exp \left(-0,583428 X_{3}-0,422888 X_{9}\right)
$$

Berdasarkan persamaan tersebut, variabel persalinan ditolong tenaga kesehatan $\left(X_{3}\right)$ dengan nilai parameter $\hat{\beta}=-0,583428$ diperoleh nilai eksponensial 0,55798 . Nilai tersebut menunjukkan bahwa semakin tinggi persentase persalinan yang ditolong tenaga kesehatan maka jumlah kematian ibu cenderung menurun.

Sedangkan untuk variabel ibu nifas mendapat vitamin $\mathrm{A}\left(X_{9}\right)$ dengan nilai parameter $\hat{\beta}=$ 0,422888 diperoleh nilai eksponensial 1,52636. Nilai tersebut menunjukkan bahwa semakin tinggi persentase ibu nifas mendapat vitamin A maka jumlah kematian ibu cenderung meningkat.

\section{KESIMPULAN}

Berdasarkan pembahasan hasil analisis yang diperoleh, persalinan yang ditolong tenaga kesehatan secara signifikan terhadap jumlah kematian ibu di Provinsi Sulawesi Selatan. Ketika suatu persalinan dibantu atau ditolong oleh tenaga kesehatan maka kemungkinan terjadinya risiko kematian cukup kecil karena ketersediaan alat dan tenaga yang ahli di bidangnya. Faktor lain yang berpengaruh terhadap jumlah kematian ibu ialah persentase ibu nifas mendapat vitamin A.

\section{DAFTAR PUSTAKA}

[1] Dinas Kesehatan Provinsi Sulawesi Selatan. "Profil Kesehatan Provinsi Sulawesi Selatan". Makassar: Dinas Kesehatan Provinsi Selawesi Selatan.

[2] Ma'sum, dkk. 2011. “Analisis Angka Kematian Ibu Menggunakan Model Regresi Binomial Regresi ( Studi Kasus: Angka Kematian Ibu di Provinsi Jawa Timur Tahun 2011)'.'Semarang: Universitas Diponegoro, Prosiding Seminar Nasional Statistika. ISBN: 978602-14387-0-1).

[3] Walpole, Ronald E dan Myers, Raymond H. 1995. "Ilmu Peluang Dan Statistika Untuk Insinyur Dan Ilmuwan Terjemahan RK Sembiring”. Bandung: Penerbit ITB.

[4] JW, Hardin and JM, Hilbe. 2007. "Generalized Linear Models and Extensions Second Edition”. USA: Stata Press Publication. 
[5] Pradawati, Putu Susan, dkk. "Penerapan Regresi Binomial Negatif Untuk Mengatasi Overdispersi Pada Regresi Poisson". E-Jurnal Matematika, Vol.2 No.2 (2013).

[6] Fatima, Fiona Harva, dkk. "Pemodelan Angka Kematian Bayi di Kabupaten Kuningan Tahun 2014 Dengan Regresi Generalized Poisson dan Regresi Binomial Negatif". Prosiding Statistika, ISSN: 2460-6456, Vol.2 No.2 (Agustus 2016).

[7] Wahyuni, Widya. 2011. "Penaksir Parameter Model Regresi Binomial Negatif pada Kasus Overdispersi”. Depok: Universitas Indonesia.

[8] Ma'sum, dkk. 2011. “Analisis Angka Kematian Ibu Menggunakan Model Regresi Binomial Regresi ( Studi Kasus: Angka Kematian Ibu di Provinsi Jawa Timur Tahun 2011)'.'Semarang: Universitas Diponegoro, Prosiding Seminar Nasional Statistika. ISBN: 978602-14387-0-1).

[9] Dinas Kesehatan Provinsi Sulawesi Selatan. 2015. "Profil Kesehatan Provinsi Sulawesi Selatan Tahun 2015". Makassar: Dinas Kesehatan Provinsi Selawesi Selatan. 